\title{
Effect of Refining Parameters on Medium Density Fibreboard (MDF) Properties from Oil Palm Trunk (Elaeis guineensis)
}

\author{
Zawawi Ibrahim $^{1 *}$, Astimar Abdul Aziz ${ }^{1}$, Ridzuan Ramli ${ }^{1}$, Anis Mokhtar ${ }^{1}$, SiJoon Lee ${ }^{2}$ \\ ${ }^{1}$ Engineering \& Processing Division, Malaysian Palm Oil Board, Selangor, Malaysia; ${ }^{2}$ Dongwha Chemical Malaysia Sdn Bhd, \\ Dongwha Malaysia Holdings Sdn Bhd, Kuala Lumpur, Malaysia. \\ Email: " zawawi.ibrahim@gmail.com
}

Received September $19^{\text {th }}, 2013$; revised October $5^{\text {th }}, 2013$; accepted October $9^{\text {th }}, 2013$

Copyright (C) 2013 Zawawi Ibrahim et al. This is an open access article distributed under the Creative Commons Attribution License, which permits unrestricted use, distribution, and reproduction in any medium, provided the original work is properly cited.

\begin{abstract}
The properties of medium density fibreboard (MDF) made from oil palm trunk (OPT) as affected by refining pressure and preheating time were investigated. The OPT chips were refined in the MDF pilot plant by using four refining pressures $(2,4,6$ and 8 bar) and four different preheating time (100, 200, 300 and 400 seconds). The refined fibres were blended with $10 \%$ of urea formaldehyde with a board target density of $720 \mathrm{~kg} / \mathrm{m}^{3}$. MDF boards were evaluated based on European Standard EN 622-5:2006 for thickness swelling (TS), internal bonding (IB), modulus of rupture (MOR) and modulus of elasticity (MOE). Analysis of variance (ANOVA) was used to analyze the significance of the factors. The results from this study indicated that refining pressure and preheating time are significant factors for all MDF properties. Low refining pressure and preheating time produced higher TS, lower MOR and MOE with poor bonding than those boards prepared from fibres refined at higher refining pressure and longer preheating time. OPT fibre treated with 8 bar produced good swelling resistance but detrimental on mechanical properties of the finish board. 6 bar steam pressure offered the highest value of mechanical properties (MOE, MOR and IB). Boards from intermediate refining condition (6 bar and 300 seconds) were found the better board properties having $14.58 \%, 0.73 \mathrm{~N} / \mathrm{mm}^{2}, 38 \mathrm{~N} / \mathrm{mm}^{2}$ and 3597 $\mathrm{N} / \mathrm{mm}^{2}$ for TS, IB, MOR and MOE respectively.
\end{abstract}

Keywords: Oil Palm Trunk; Medium Density Fibreboard; Refining Pressure; Preheating Time

\section{Introduction}

The oil palm industry is one of the largest industries in Malaysian crop and plantation area covering about 5.08 million ha planted area [1]. The main production is the palm oil, but the oil produced only about $10 \%$ of the total biomass from oil palm tree, meanwhile the remaining is in the form of solid biomass. The residues include oil palm trunks (OPT), oil palm fronds (OPF), oil palm empty fruit bunch (EFB), mesocarp fibres and palm kernal shells. The total biomass was estimated about 90 million tonnes per year with 8.2 million tonnes of OPT, 12.9 million tonnes of OPF and 15.8 million tonnes of EFB $[2,3]$. Some of these are being used as fuel, fertilizer, animal feed and in composites $[4,5]$.

Oil palm trunk (OPT) is available during replanting in which the economic life span of oil palm tree is declining

*Corresponding author. at age about 25 - 30 years. With the implementation zero burning policy by Malaysian Government, there are huge amount of felled OPT available during the replanting. The OPT can be utilized for many applications such as plywood, laminated veneer lumber, particleboard, fibreboard and chemical derivates. Due to the shortage of wood in the wood based industry, such as the fibreboard and the availability of this OPT, some interests have been drowned towards using the OPT as a material for medium density fibreboard (MDF) industry.

Refining is the process referring to the production of refined fibres from chips and thermo-mechanical pulping (TMP) is mainly the process used for refined fibres production in pulp and fibreboard industries. In the MDF manufacture, refining conditions play important function to produce good quality of fibres and these conditions affect the performance of final board properties. In common TMP process, refining pressure and preheating time 
are the two main manufacturing parameters that influence these properties. The refining stage, refining pressure is the dominant factor that leads to the quality of the fibres [6]. Many researchers have indicated that refining conditions have obvious effects on the final MDF properties. The increasing of refining pressure results in low MOR and MOE values, with better dimensional properties [7]. High refining pressure reduced the thickness swelling (TS) of the boards [8]. MDF manufactured at higher refining pressure resulted in lower MOR, MOE and IB strength due to the reduction in fibre length and having poor fibre contact [9]. The fibreboard from oil palm produced under higher pressure resulted in high IB but low MOR value [10]. They also reported that high pressure and preheating time resulted in better dimensional stability as the fibres lost its elasticity. In addition, the fibre refined under higher refining pressure and preheating time had better IB value because these conditions leaded to better self-bonding ability [11].

The objective of this investigation is to evaluate the effects of refining pressure and preheating time during the refining process in the production of MDF from oil palm trunk.

\section{Material and Method}

\subsection{Material Preparation}

The raw material for this study was the trunk collected from oil palm plantation located at FELDA Keratong, Pahang. The trunks were manually cut and were chipped using a chipper. The chips were refined using the SproutBauer (ANDRITZ) refiner at the MDF pilot plant located in MPOB/UKM Research Station, following the parameters as stated in Table 1. After refining, the refined fibres were dried in the oven until the moisture content (MC) is about $4 \%-5 \%$.

\subsection{MDF Boards Preparation and Properties Evaluation}

The OPT refined fibres were blended with emulsion wax and urea formaldehyde (UF) as the adhesive in the glue blender machine. A wooden former with the dimension of $300 \times 300 \mathrm{~mm}$ was used in this study. The fibres were manually formed into a single layer mat followed by pre-press and finally hot-pressed. The parameters for the MDF production are presented in Table 2.

The boards were kept conditioned at temperature of $22^{\circ} \mathrm{C}$ and relative humidity of $65 \%$ until it reached equilibrium moisture content before testing. The boards were cut into specific sizes before testing. The mechanical properties for IB $(50 \times 50 \mathrm{~mm})$ and static bending strength $(290 \times 50 \mathrm{~mm})$ were tested using Zwick $10 \mathrm{kN}$ Universal Testing Machine. The TS $(50 \times 50 \mathrm{~mm})$ were
Table 1. Refining parameters used with four different refining pressure and time.

\begin{tabular}{cc}
\hline Refining Pressure (Bar) & Preheating Time (Seconds) \\
\hline 2 & 100 \\
4 & 200 \\
6 & 300 \\
8 & 400 \\
\hline
\end{tabular}

Table 2. The MDF of OPT manufacturing parameters.

\begin{tabular}{cc}
\hline Processing Parameter & Value \\
\hline Target MC of fibres after oven dry (\%) & $4-5$ \\
Urea formaldehyde (UF) content (\%) & 10 \\
Solid content of UF resin (\%) & 64 \\
Emulsion wax content (\%) & 0.5 \\
Hardener $(\mathrm{g})$ & - \\
Target MC after blending (\%) & $8-10$ \\
Board density $\left(\mathrm{kg} \cdot \mathrm{m}^{-3}\right)$ & 720 \\
Board dimension $(\mathrm{mm})$ & $300 \times 300$ \\
Board thickness $(\mathrm{mm})$ & 12 \\
Pressing temperature $\left({ }^{\circ} \mathrm{C}\right)$ & 200 \\
Pressing time $(\mathrm{min})$ & 5 \\
\hline
\end{tabular}

carried out by $24 \mathrm{~h}$ immersed in the water. All the properties were tested according to European Standard EN 622-5:2006 [12].

\subsection{Data Analysis}

The Analysis of Variance (ANOVA) was conducted, and T-test was used by using Least Significant Difference (LSD) method (Statistical Analysis System (SAS) software) to compare the mean values of TS, IB, MOR and MOE of the boards under various refining condition at the $95 \%$ confident level.

\section{Results and Discussion}

\subsection{Analysis of Variance (ANOVA) of the Refining Parameters}

The results of analysis of variance (ANOVA) for all parameters are listed in Table 3. It shows that the effects of refining pressure and preheating time have significant effects $(p \leq 0.01)$ towards the TS, IB, MOR and MOE. The interaction between refining pressure and preheating time factors also significantly affected the TS, IB and MOR at $p \leq 0.01$, and MOR at $p \leq 0.05$.

The mean value according to least significant difference (LSD) of TS, IB, MOR and MOE are given in Table 4. 
Table 3. Table of analysis of variance (ANOVA) on the board properties.

\begin{tabular}{ccccc}
\hline Parameter & \multicolumn{3}{c}{ Pr $>$ F } & \\
\cline { 2 - 5 } & TS & IB & MOR & MOE \\
\hline Refining pressure (RP) & $<0.0001^{* * *}$ & $0.0002^{* * *}$ & $<0.0001^{* * *}$ & $<0.0001^{* * *}$ \\
Preheating time (PT) & $0.0008^{* * *}$ & $<0.0001^{* * *}$ & $<0.0001^{* * *}$ & $<0.0001^{* * *}$ \\
Interaction between RP $\times$ PT & $<0.0001^{* * *}$ & $<0.0001^{* * *}$ & $0.0115^{* *}$ & $<0.0001^{* * *}$ \\
\hline
\end{tabular}

Note: ${ }^{* * *}$ Significantly different at $p \leq 0.01 ;{ }^{* *}$ Significantly different at $p \leq 0.05$.

Table 4. The mean value of board properties: TS, IB, MOR and MOE.

\begin{tabular}{|c|c|c|c|c|c|}
\hline Refining pressure (bar) & Preheating time (seconds) & TS (\%) & IB $\left(\mathrm{N} / \mathrm{mm}^{2}\right)$ & $\operatorname{MOR}\left(\mathrm{N} / \mathrm{mm}^{2}\right)$ & $\operatorname{MOE}\left(\mathrm{N} / \mathrm{mm}^{2}\right)$ \\
\hline \multirow{4}{*}{2} & 100 & $20.50^{\mathrm{a}}$ & $0.59^{\mathrm{c}}$ & $29.80^{\mathrm{e}}$ & $2829^{d}$ \\
\hline & 200 & $19.02^{\mathrm{b}}$ & $0.64^{\mathrm{b}}$ & $30.07^{\mathrm{e}}$ & $2935^{d}$ \\
\hline & 300 & $19.18^{\mathrm{b}}$ & $0.61^{\mathrm{c}}$ & $31.77^{\mathrm{d}}$ & $2918^{d}$ \\
\hline & 400 & $18.11^{\mathrm{c}}$ & $0.66^{\mathrm{b}}$ & $32.07^{\mathrm{d}}$ & $2809^{d}$ \\
\hline \multirow{4}{*}{4} & 100 & $16.83^{\mathrm{c}}$ & $0.64^{\mathrm{b}}$ & $37.63^{\mathrm{b}}$ & $3418^{\mathrm{b}}$ \\
\hline & 200 & $17.39^{\mathrm{d}}$ & $0.62^{\mathrm{b}}$ & $37.14^{\mathrm{b}}$ & $3355^{\mathrm{b}}$ \\
\hline & 300 & $16.42^{\mathrm{d}}$ & $0.70^{\mathrm{a}}$ & $36.52^{\mathrm{b}}$ & $3349^{\mathrm{b}}$ \\
\hline & 400 & $17.19^{d}$ & $0.71^{\mathrm{a}}$ & $36.80^{\mathrm{b}}$ & $3192^{\mathrm{c}}$ \\
\hline \multirow{4}{*}{6} & 100 & $15.69^{\mathrm{e}}$ & $0.68^{\mathrm{b}}$ & $38.31^{\mathrm{a}}$ & $3444^{\mathrm{a}}$ \\
\hline & 200 & $14.63^{\mathrm{f}}$ & $0.72^{\mathrm{a}}$ & $39.89^{\mathrm{a}}$ & $3538^{\mathrm{a}}$ \\
\hline & 300 & $14.58^{\mathrm{f}}$ & $0.73^{\mathrm{a}}$ & $38.33^{\mathrm{a}}$ & $3597^{\mathrm{a}}$ \\
\hline & 400 & $14.37^{\mathrm{f}}$ & $0.73^{\mathrm{a}}$ & $35.14^{\mathrm{b}}$ & $3421^{\mathrm{a}}$ \\
\hline \multirow{4}{*}{8} & 100 & $13.38^{\mathrm{g}}$ & $0.64^{\mathrm{b}}$ & $37.59^{\mathrm{b}}$ & $3361^{\mathrm{b}}$ \\
\hline & 200 & $13.05^{\mathrm{g}}$ & $0.62^{\mathrm{b}}$ & $37.39^{\mathrm{b}}$ & $3312^{\mathrm{b}}$ \\
\hline & 300 & $12.82^{\mathrm{g}}$ & $0.64^{\mathrm{b}}$ & $35.07^{\mathrm{c}}$ & $3309^{\mathrm{b}}$ \\
\hline & 400 & $12.81^{\mathrm{g}}$ & $0.54^{\mathrm{c}}$ & $33.74^{\mathrm{c}}$ & $3287^{b}$ \\
\hline \multicolumn{2}{|c|}{ Minimum Requirement EN 622-5:2006 } & 15.00 & 0.60 & 22.00 & 2500 \\
\hline
\end{tabular}

Note: Means followed by same letters in each column are not significantly different at $\mathrm{p} \leq 0.05$ according to least significant difference (LSD) method.

\subsection{The Effects of Refining Pressure and Preheating Time on the Thickness Swelling of the Boards}

The boards from higher and longer refining pressure and preheating time showed low TS. The TS value decreased with the increasing of refining pressure and preheating time. This may be due to the removal of hemicelluloses that is hydrophilic component resulted from refining process [13].

Higher refining pressure generated more individual and short fibres, thus increased the effective surface area and absorbs less water [14]. The higher the proportion of shorter fibre, the higher the bulk density of the board [15]. This is due to the fact that shorter fibres make denser structures between fibres and resulted in larger contact of fibre-to-fibre area during hot pressing, and finally pro- duced larger bonding area and lower porosity. These conditions produced board with better dimensional properties.

Except for the boards prepared from the fibres refined at 2 and 4 bar at all preheating time, and also at 6 bar for 100 seconds of preheating time, boards made with other refining conditions showed TS below $15 \%$ and meet the minimum requirements of EN 622-5:2006.

\subsection{The Effect of Refining Pressure and Preheating on the Internal Bonding of the Boards}

The value of IB increased with the increasing of refining pressure and preheating time from 2 bar (at all preheating time) to 6 bar (at all preheating time), but decreased with a further increased in refining pressure of 8 bar and 
longer preheating time. Refining at 2 bar at 100 seconds, the IB value was $0.59 \mathrm{~N} / \mathrm{mm}^{2}$, but the value increased to $0.66 \mathrm{~N} / \mathrm{mm}^{2}$ when the preheating time was increased to 400 seconds. The board from 6 bar of refining pressure showed highest IB value.

The value of IB increase due to the fact that short fibre (resulted from severe refining conditions) increased the bonding area, thus improve the bonding by developing more interlocking fibre-to-fibre bonding. Using higher steam pressure during the refining process has increased the IB value of fibreboard prepared from miscanthus sinensis [16].

Furthermore, during refining, the hemicellulose were hydrolyzed, thus increase the amount of by product materials. Refining causes decomposition of the hemicellulose and convert it into water-soluble carbohydrates, which could act as a binding agent for the fibres $[17,18]$. Using steam pressure of $0.6-1.0 \mathrm{MPa}$ for 5 minutes for the refining of sugarcane, the hemicellulose content was decreased as the steam pressure and time increased [19].

Refining pressure of 8 bar, the IB values decreased possibly due to the severe refining condition resulted in excess of fine fibres [20]. More short and fine fibres resulted in higher fibre surface area that expose to bonding with other fibres. The $10 \%$ UF is not distributed well into the fibres surface area, created fibres with less UF penetration, and influences the bonding properties. Except for the boards from fibres refined at 2 bar for 100 seconds, the IB of all boards exceeded the requirements.

\subsection{The Effect of Refining Pressure and Preheating on the Bending Strength of the Boards}

The MOR and MOE value increased significantly when the refining pressure and preheating time increased from 2 to 8 bar, and from $100-400$ seconds respectively. At the refining condition of 2 bar for 100 seconds, the MOR and MOE value were $29.8 \mathrm{~N} / \mathrm{mm}^{2}$ and $2829 \mathrm{~N} / \mathrm{mm}^{2}$, respectively. And at 6 bar for 100 seconds, the MOR and MOE value were increased to 35.14 and $3421 \mathrm{~N} / \mathrm{mm}^{2}$. This trend of MOR and MOE are similar to the IB trend, where the value decreased at severe refining pressure $(8$ bar) and longer the preheating time.

Higher refining condition significantly increased both MOR and MOE value. This could be due to the more individual fibres were generated, thus higher percentage of overlap between two fibres resulted in better fibre-tofibre orientation and arrangement. The fibre geometry, fibre orientation, fibre arrangement and fibre volume factors controls many mechanical properties [21]. The bending strength (MOR and MOE) improved when refining steam pressure increases [22].

At 8 bar of refining pressure, however, increasing the preheating time results in lower MOR and MOE value. This could be attributed to the damage fibre cell walls. Higher refining pressure destroyed lumen and S3 layer due to the explosion caused by the higher pressure inside the lumen during refining [23]. The nano-cracks in fibres also generated by higher refining pressure, and influence the strength of the fibres.

\section{Conclusion}

The refining pressure and preheating time process of OPT chips play significant factors toward determining the MDF board properties. Low refining conditions give poor dimensional stability and bonding, and low bending strength. OPT fibre refined with 8 bar produces better swelling properties but detrimental in mechanical properties. The optimum refining parameters in producing MDF from OPT are 6 bar of refining pressure and 300 seconds of preheating time.

\section{Acknowledgements}

The author wish to thank the Director General of MPOB for permission to publish this paper.

\section{REFERENCES}

[1] MPOB, "Malaysian Oil Palm Statistics 2012," 32nd Edition, Malaysia Palm Oil Board, Ministry of Plantation \& Commodities, Kajang, 2013.

[2] S. Sumathi, S. P. Chai and A. R. Mohamed, "Utilization of Oil Palm as a Source of Renewable Energy in Malaysia," Renewable \& Sustainable Energy Reviews, Vol. 12, No. 9, 2008, pp. 2404-2421. http://dx.doi.org/10.1016/j.rser.2007.06.006

[3] M. Z. Alam, A. A. Mamun, I. Y. Qudsieh, S. A. Muyibi, H. M. Salleh and N. M. Omar, "Solid State Bioconversion of Oil Palm Empty Fruit Bunches for Cellulose Enzyme Production Using a Rotary Drum Bioreactor," Biochemical Engineering Journal, Vol. 46, No. 1, 2009, pp. 61-64.

[4] R. Hashim, L. S. How, R. N. Kumar and O. Sulaiman, "Some of the Properties of Flame Retardant Medium Density Fibreboard Made from Rubberwood and Recycled Containers Containing Aluminium Trihydroxide," Bioresource Technology, Vol. 96, No. 16, 2005, pp. 18261831. http://dx.doi.org/10.1016/j.biortech.2005.01.023

[5] M. Jawaid, H. P. S. Abdul Khalil, K. P. Noorunisa and A. Abu Bakar, "Hybrid Composites Made from Oil Palm Empty Fruit Bunches/Jute Fibres: Water Absortion, Thickness Swelling and Density Behaviour," Journal of Polymers and the Environment, Vol. 19, No. 1, 2010, pp. 106109.

[6] C. Xing, S. Wang and G. M. Pharr, "Nanoindention of Juvenile and Mature Loblolly Pine (Pinus taeda L.) Wood Fibres as Affected by Thermomechanical Refining Pressure," Wood Science and Technology, Vol. 43, 2009, 
615-625.

[7] D. Krug and E. Kehr, "Influence of High Pulping Pressures on Permanent Swelling-Tempered Medium Density Fibreboard," Holz als Roh-und Werkstoff, Vol. 59, 2001, pp. 342-343.

[8] E. Roffael, B. Dix and T. Schneider, "Thermomechanical (TMP) and Chemo-Thermomechanical Pulps (CTMP) for Medium Density Fibreboard (MDF)," Holzforschung, Vol. 55, No. 2, 2001, pp. 214-218.

[9] L. H. Groom, L. Mott and S. M. Shaler, "Relationship between Fibre Furnish Properties and the Structural Performance of MDF," 33rd International Particleboard/ Composite Materials Symposium Proceedings, Washington State University, Pullman, Washington DC, 13-15 April 1999, pp. 89-100.

[10] N. Laemsak and M. Okuma, "Development of Boards Made from Oil Palm Frond II: Properties of Binderless Boards from Steam-Exploded Fibers of Oil Palm Frond," Journal Wood Science, Vol. 46, No. 4, 2000, pp. 322-326. http://dx.doi.org/10.1007/BF00766224

[11] Z. Gao, X. Wang, H. Wan and G. Brunette, "Binderless Panels Made with Black Spruce Bark," BioResources, Vol. 6, No. 4, 2011, pp. 3960-3972.

[12] Anon, "BS EN 622-5:2006. European Standard Fibreboards Specifications. Part 5. Requirements for Dry Process Boards (MDF)," CEN (European Committee for Standardization), London, 2006.

[13] J. Xu, R. Widyorini, H. Yamauchi and S. Kawai, "Development of Binderless Fibreboard from Kenaf Core," Journal of Wood Science, Vol. 52, No. 3, 2006, pp. 236243. http://dx.doi.org/10.1007/s10086-005-0770-3

[14] C. Xing, S. Wang and G. M. Pharr, "Nanoindention of Juvenile and Mature Loblolly Pine (Pinus taeda L.) Wood Fibres as Affected by Thermomechanical Refining Pressure," Wood Science and Technology, Vol. 43, No. 7-8, 2009, pp. 615-625. http://dx.doi.org/10.1007/s00226-009-0266-1

[15] C. Xing, J. Deng, S. Y. Zhang, B. Riedl and A. Cloutier,
"Properties of MDF from Black Spruce Tops as Affected by Thermomechanical Refining Conditions," Holz als Roh-und Werkstoff, Vol. 64, No. 6, 2006, pp. 507-512.

[16] J. A. Velasquez, F. Ferrando and J. Salvado, "Binderless Fibreboard from Steam Exploded Miscanthus sinensis: The Effect of Grinding Process," Holz als Roh-und Werkstoff, Vol. 60, No. 4, 2002, pp. 297-302.

[17] J. Xu, G. Han and S. Kawai, "Development of Binderless Particleboard from Kenaf Core Using Sream-Injection Pressing," Journal of Wood Science, Vol. 49, No. 4, 2003, pp. 327-332. http://dx.doi.org/10.1007/s10086-002-0485-7

[18] H. E. Hsu, W. Schwald and J. A. Shields, "Chemical and Physical Changes Required for Producing Dimensionally Stable Wood-Based Composites," Wood Science and Technology, Vol. 22, No. 3, 1988, pp. 281-289. http://dx.doi.org/10.1007/BF00386023

[19] H. Okamoto, S. Sano, S. Kawai, T. Okamoto and H. Sasaki, "Production of Dimensionally Stable Medium Density Fibreboard by Use of High Pressure Steam Pressing," Mokuzai Gakkaishi, Vol. 40, No. 4, 1994, pp. 380-389.

[20] H. A. Aisyah, M. T. Paridah, M. H. Sahri, A. A. Astimar and U. M. K. Anwar, "Properties of Medium Density Fibreboard (MDF) from Kenaf (Hibiscus cannabinus L.) Core as Function of Refining Conditions," Composite Part B, Vol. 44, No. 1, 2013, pp. 592-596.

[21] D. Hull and T. W. Clyne, "An Introduction to Composite Materials," Cambridge University Press, Cambridge, 1996. http://dx.doi.org/10.1017/CBO9781139170130

[22] N. Ayrilmis, "Effect of Tree Species on Technological Properties of Medium Density Fibreboard," M.Sc. Thesis, Institute of Natural Science, Istanbul University, Fatih/ Istanbul, 2000.

[23] C. Xing, S. Wang, G. M. Pharr and L. H. Groom, "Effect of Thermo-Mechanical Refining Pressure on the Properties of Wood Fibers as Measured by Nano-indentation and Atomic Force Microscopy," Holzforschung, Vol. 62, No. 2, 2008, pp. 230-236. 